\title{
CDISC SEND Sexual Maturity Status Response Terminology
}

National Cancer Institute

\section{Source}

National Cancer Institute. CDISC SEND Sexual Maturity Status Response Terminology. NCI Thesaurus. Code C158124.

Terminology associated with the sexual maturity status response codelist of the Clinical Data Interchange Standards Consortium (CDISC) Standard for the Exchange of Nonclinical Data (SEND). 